This was the achievement of John Daiton who worked out his atomic theory during the years 1803 to 1808 . By assigning relative weights to the atoms Dalton was to give them a positive meaning which could be related to chemical practice. The exercises of Halley and others in the seventeenth century could only lead to despair or wonder. As man was beginning to learn of the immensity of space he was also learning of the existence of a micro-world equally inaccessible to his direct experience. Man was becoming the measurer rather than the measure of all things.

\section{References}

1 Discourse and Opinions of Galileo, translated by Stillman Drake, New York, Doubleday, 1957, p. 267
2 Dialogue Concerning Two New Sciences, translated by Henry Crew and Alfonso de Salvio, New York, Macmillan, 1914, p. 48

3 Ibid., pp. 52-53

4 Ibid., pp. 54-55

5 More details of this and other contributions to matter theory are discussed in M. P. Crosland, The Science of Matter. A Historical Survey, London, Penguin paperback, 1971

6 Phil. Trans. Roy. Soc., 1691, 16, (194), pp. 541-2

7 Ibid., (194), p. 575

8 Opticks, Book Two, Part III, 4th edition, London 1730 , Dover reprint, New York, 1952, p. 267

9 Priestley, Disquisitions Relating to Matter and Spirit, London, 1777, p. 17. Annold Thackray, Atoms and Powers. An Essay on Newtonian Matter Theory and the Development of Chemistry, Cambridge, Mass., 1970

10 Robert Boyle, Sceptical Chymist, 1661, modern edition, Dent, 1911 , p. 31

\title{
Advances in Gold Extraction and Refining
}

Gold Metallurgy in South Africa EDITED BY R. J. ADAMSON

Pp. XI and 452. Chamber of Mines of South Africa, Johannesburg, R14.00

Since the beginning of gold mining on the Witwatersrand in 1886 the total amount of gold extracted in South Africa has reached one thousand million ounces, or more than thirty thousand tons. This immense output-obtained from over 3,000 million tons of ore-has been achieved by a combination of technical expertise and co-operative effort in the development of improved methods of ore treatment, smeiting and refining.

When the Witwatersrand reef was first exploited, established methods of extraction then in use elsewhere in the world were naturally adopted or adapted, but these were quickly followed by more advanced and specialised processes designed to ensure the maximum recovery of gold from the relatively low grade of ore. It is now well over twenty years since a text book covering these techniques was made available-King's "Gold Metallurgy on the Witwatersrand" was published in 1949-and developments in the meantime, particularly those stimulated by the opening of the newer mines in the Orange Free State, have made the methods then described no longer representative of current practice.

While the basic methods of concentration and cyanidation introduced many years ago still form the most satisfactory and economical means of extraction, many improvements have been made in their application and in the necessary equipment, and it is mainly in order to describe these more recent developments that the preparation of this book has been undertaken by a team of metallurgists, drawn from the major mining groups and from the National Institute for Metallurgy, under the chairmanship of Mr Adamson, Metallurgical Consultant to the Chamber of Mines.

Because gold in South African ores is intimately associated with a matrix of quartz and other minerals the first step towards its recovery involve comminution to fine particle sizes in order to release the gold for further treatment. The successive stages of crushing and grinding, milling and classification are described at length, with full details of developments in the mechanical equipment. Gravity concentration pro- cedures are similarly discussed, followed by a full account of the cyanidation process first introduced by MacArthur and the Forrest brothers in 1890 but nowadays characterised by much more sophisticated filtration practice and operated as a continuous instead of a batch process.

Precipitation of the gold from the cyanide solution is effected by means of metallic zinc, the gold slimes being separated in pressure filters. These are acid-treated to remove as much zinc as possible, calcined, mixed with a borax and silica flux and smelted in submerged arc furnaces. When smelting is complete the three carbon electrodes are raised mechanically and the furnace tilted for pouring into 1000 ounce $(31 \mathrm{~kg})$ bars. The product at this stage averages 10 per cent silver and 2 to 3 per cent of copper, iron, zinc and lead, with traces of the platinum metals.

Final refining is carried out in the Rand Refinery, where a modernisation programme has been completed resulting in virtually an entirely new plant. Its operations were briefly described in Gold Bulletin in April 1971 , but in the present book a fully detailed account is given of both the chlorine refining and the electrolytic refining procedures and of the rapid and economical handling of a very large output of refined gold.

A further section reviews recent progress in instrumentation and process control in South African gold plants, while a chapter on the chemistry of gold extraction includes an intriguing discussion on the use of Pourbaix diagrams in predicting the behaviour of gold in various conditions and in the selection of reagents and conditions that will favour its dissolution or alternatively its precipitation from solution.

As Sir Thomas Rose wrote in the preface to his "Metallurgy of Gold" many years ago:

"The most important function which a book on metallurgy has to fulfil is to help those who are taking part in attempts to improve the existing practice."

The present work certainly complies with this prescription as well as constituting a standard text for the student and the research worker.

L. B. $\mathbf{H}$, 